\title{
Therapeutic Options in Advanced Laryngeal Cancer: An Overview
}

\author{
Fernando L. Dias ${ }^{a}$ Roberto A. Lima ${ }^{a}$ Jacob Kligerman ${ }^{a}$ Claudio R. Cernea ${ }^{b}$ \\ ${ }^{a}$ Head and Neck Surgery Service, Instituto Nacional de Cancer/INCA, Rio de Janeiro, and

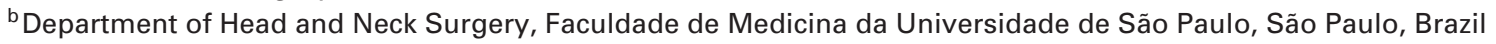

\section{Key Words}

Larynx $\cdot$ Cancer $\cdot$ Treatment $\cdot$ Surgery $\cdot$ Radiotherapy

\begin{abstract}
Historically, patients with advanced laryngeal cancer have been treated with radical surgery and adjuvant radiation therapy. Intensive surgical research has allowed surgeons to deal with almost any local extension and to propose an appropriate surgical procedure for each case. Several function-sparing surgical options are available to treat moderately advanced/advanced laryngeal cancer. Better understanding of the anatomy and biology of cancer in this anatomical site has enabled us to devise effective oncological strategies associated with a great effort to preserve laryngeal function. Numerous efforts have been made to augment the therapeutic armamentarium with the addition of chemotherapeutic agents combined with radiation therapy. For advanced laryngeal cancer, the debate is still open between partial/subtotal surgical procedures, which are more efficient but sacrifice parts of the larynx, and radiotherapy/chemoradiation protocols which can preserve the larynx and its function even though it requires radical surgery for salvage. Efforts should be made to select patients properly, in an individual basis, based on tumor characteristics, clinical aspects, patient's expectations, and the expertise of the head and neck oncologic team for the various therapeutic strategies in order to get better oncological results in association with the preservation of the laryngeal form and function, when possible.
\end{abstract}

Copyright (C) 2005 S. Karger AG, Basel

\section{KARGER}

Fax +4161306 1234 E-Mail karger@karger.ch www.karger.com

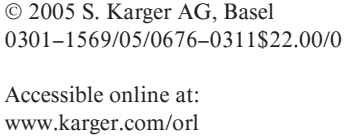

\section{Introduction}

The introduction of the bioanatomic concepts of conservation laryngeal cancer was the result of the works of Frazer, Tucker, Pressman, Kirschner [1, 2], and others [3]. These studies demonstrated the relationship between the embryological and anatomical characteristics of the larynx as well as the biological behavior of laryngeal tumors. The concept that natural (architectural) barriers within the cartilaginous and ligamentous laryngeal framework could prevent the downward expansion of supraglottic cancer had been observed clinically too. Lesions arising on the laryngeal surface of the epiglottis may spread superficially and laterally to involve most of the epiglottic surface. The second, and frequent, step is the invasion of the epiglottic cartilage, penetrating through the lacunae into the pre-epiglottic space. The pre-epiglottic space may also be invaded by the tumor spreading around the lateral edge of the epiglottis. Once tumors involve the pre-epiglottic space, they may spread inferiorly extending to the epiglottic petiole, and the anterior commissure [3]. Although quite large they may be confined to the supraglottic anatomical area, so that a supraglottic laryngectomy can encompass the lesion. Tucker and Smith [4] histologically demonstrated that elastic tissue barriers (laryngeal ligaments and cartilages) within the larynx provide the anatomical basis for these observations. Studies of Coutard and Valat [5], and Bocca et al. [6] and others confirmed the observations that supraglottic tumors generally do not invade the glottis and remained above the ventricle. They also attributed that

Fernando L. Dias, MD, FACS

Chief, Head and Neck Surgery Department

Instituto Nacional de Câncer

Rio de Janeiro, R.J. 20230-130 (Brazil)

Tel. +55 212506 6189/8844-3880, Fax +55 212527 2333, E-Mail fdias@inca.gov.br 
characteristic to the fact that the supraglottic larynx develops separately from the glottis. The anterior commissure ligament may also serve as a barrier to the inferior spread of supraglottic tumors, but if it becomes grossly involved it may serve as a route of invasion to the thyroid cartilage. On the other hand, tumors of the ventricle invade the paraglottic space early and rapidly become transglottic, invade cartilage and spread to extralaryngeal areas. Once the tumor crosses the ventricle inferiorly, either by mucosal spread or paraglottic space extension, they are termed transglottic tumors. The paraglottic space extends along the three laryngeal regions and communicates with the pre-epiglottic space, anteriorly. The right and left paraglottic spaces also communicate just below the anterior commissure, where an area of minor resistance is represented by the point of entry of the anteroinferior laryngeal artery in the conoid ligament. The indications of subtotal laryngectomy must, therefore, bear these concepts in mind. The inferior paraglottic space, on the other hand, tends to be narrow, forming an acute angle at the junction of the conus elasticus and the free margin of the cricoid cartilage, giving rise to an area susceptible to neoplastic microinfiltration. Most of the times, there is no evident infiltration of the subglottic area at this level, at endoscopic evaluation. Another important point of consideration is the role of conus elasticus as a barrier to tumor progression. Although it is a natural obstacle to tumor progression, it becomes weaker with aging, and once tumor infiltration occurs, the risks of tracheal invasion increase.

\section{Therapeutic Options for Advanced Supraglottic Cancer}

The treatment options for the advanced supraglottic laryngeal cancer includes: radiation therapy, transoral laser excision, partial laryngectomies, total laryngectomy, and chemoradiation.

Selected advanced supraglottic cancer can be successfully treated with radiotherapy (RT) alone. Mendenhall et al. [7] characterized what they called an unfavorable (for RT treatment) advanced supraglottic cancer. These lesions included all T4 tumors and T3 lesions with high volume (at $\mathrm{CT}$ ) with vocal cord fixation and association with airway compromise. Prognostic factors associated with higher rates of disease-free survival with RT alone for advanced supraglottic cancer include: T3 tumor classification based on the limited invasion of pre-epiglottic space $(<25 \%)$ and/or extension to the medial wall of the
Table 1. Place for definitive RT for supraglottic cancer

\begin{tabular}{lccc}
\hline Authors & Year & $\begin{array}{l}\text { T3 } \\
\text { (5-year LC) }\end{array}$ & $\begin{array}{l}\text { T4 } \\
\text { (5-year LC) }\end{array}$ \\
\hline Harwood and Hill [8] & 1983 & $30(56 \%)$ & $94(52 \%)$ \\
Mendenhall et al. [9] & 1996 & $89(68 \%)$ & $21(56 \%)$ \\
Daugaard and Sand [10] & 1998 & $168(38 \%)$ & $204(29 \%)$ \\
Santos et al. [11] & 1998 & $35(12 \%)^{*}$ & $89(14 \%) *$ \\
Sykes et al. [12] & 2000 & $83(67 \%)$ & $47(73 \%)$ \\
Hinerman et al. [13] & 2002 & $99(62 \%)$ & $28(62 \%)$ \\
\hline
\end{tabular}

$\mathrm{LC}=$ Local control.

* 5-years OS - Stage III/IV.

piriform sinus without vocal cord fixation, predominantly exophytic lesions with tumor volume $\leq 6 \mathrm{~cm}^{3}$ (based on CT), and without neck metastases. Five-year local control for supraglottic cancer treated with exclusive RT ranges from 12 to $68 \%$ for $\mathrm{T} 3$ patients, and from 14 to $73 \%$ for $\mathrm{T} 4$ patients, according to the literature (table 1).

A better understanding of supraglottic anatomy and cancer spread have also led to recent innovations in supraglottic cancer surgery: endoscopic laser surgery. The concept of endoscopic resection of supraglottic tumors is not new, but endoscopic $\mathrm{CO}_{2}$ laser surgery was introduced only in 1972 by Strong and Jako [14]. Davis et al. [15], in 1983, reported the first series of patients undergoing laser epiglottectomy. Steiner [16], in 1988, introduced the use of bivalved laryngopharyngoscope for the oncological surgery of supraglottic tumors. Finally, Zeitels et al. [17] in 1994 reported a more extensive experience with endoscopic resection of supraglottic carcinoma including selected T3 tumors. They concluded that the key to this procedure is to obtain adequate assessment of the depth of cancer involvement, what they called the invisible third dimension, which is very difficult to achieve in more advanced tumors. The relatively fast rehabilitation from endoscopic laser surgery associated with lower rates of complications in comparison with open supraglottic laryngectomy is very attractive, particularly for older or debilitated patients. Nevertheless, the results found in the literature for more advanced stages of supraglottic cancer are controversial and not reproducible. Therefore, contraindications for this procedure in supraglottic cancer, for the majority of authors in the literature, are mostly T3 and all of T4 lesions, infrahyoid involvement and extensive neck disease. Local control after transoral laser exci- 
Table 2. Transoral laser excision for supraglottic cancer

\begin{tabular}{llllc}
\hline Authors & Year & Patients & T3 (LC), \% & T4 (LC) \\
\hline Davis et al. [18] & 1991 & 14R & 50 & - \\
Steiner [19] & 1993 & 81R & 77 & 100 \\
Zeitels et al. [17] & 1994 & 23R & 63 & - \\
Rudert et al. [20] & 1999 & 34R & 78 & 38 \\
\hline
\end{tabular}

$\mathrm{R}=$ Plus radiotherapy; $\mathrm{LC}=$ local control.

sion ranges from 50 to $78 \%$ for T3 tumors and from 38 to $100 \%$ for T4 tumors (table 2).

Until 1950 total laryngectomy combined with radical neck dissection was the only acceptable procedure for advanced laryngeal cancer. Alonso [21] from Uruguay presented the original description of horizontal supraglottic laryngectomy at the Pan American Conference of Otolaryngology in 1946. Ogura [22], in 1958, introduced the one-stage supraglottic laryngectomy using a muscle flap and skin graft. Som [23], in 1959, reported a modification of Ogura's supraglottic laryngectomy technique consisting of primary closure by direct approximation of the base of the tongue to the remaining larynx by using the outer thyroid perichondrium. Other modifications of the original procedure described by Alonso [21] were published, extending the scope of supraglottic laryngectomy [24, 25]. Suitability for supraglottic laryngectomy depends on the extent and anatomical location of the tumor and the medical condition of the patient. The anatomical contraindications for supraglottic laryngectomy includes: extension on the infrahyoid epiglottis or into the ventricle within $5 \mathrm{~mm}$ of the anterior commissure and/or true vocal cords, gross involvement of the apex of the piriform sinus, cartilage invasion $(\mathrm{CI})$, extension to the arytenoids or vocal cord fixation and gross extension of the tongue base. Because most patients aspirate to some degree after the procedure, those who have compromised pulmonary or cardiac status are not good candidates for conservation surgery. Local control after supraglottic laryngectomy ranges from 62 to $100 \%$ for T3 tumors and from 41 to $100 \%$ for T4 tumors (table 3 ).

Supracricoid laryngectomy with cricohyoidopexy (SCL-CHP) arose as the surgical procedure of choice for selected supraglottic cancers with glottic extension. The technique was first described by Majer and Rieder [31] in 1959 and was later modified by Piquet et al. [32] and Laccourreye et al. [33]. The supracricoid partial laryngectomy with cricohyoidopexy (SCL-CHP) was designed for
Table 3. 5-year local control in supraglottic laryngectomy

\begin{tabular}{lccc}
\hline Authors & Year & $\begin{array}{l}\text { T3 } \\
\text { (5-year LC) }\end{array}$ & $\begin{array}{l}\text { T4 } \\
\text { (5-year LC) }\end{array}$ \\
\hline Bocca et al. [26] & 1983 & $-(72 \%)$ & $-(65 \%)$ \\
Burstein and Calcaterra [27] & 1985 & $16(94 \%)$ & $1(100 \%)$ \\
Lee et al. [28] & 1990 & $21(100 \%)$ & $4(100 \%)$ \\
Myers and Alvi [3]* & 1996 & $38(68 \%)$ & $27(52 \%)$ \\
Santos et al. [11] & 1998 & $47(62 \%)$ & $52(41 \%)$ \\
Isaacs et al. [29] & 1998 & $-(71 \%)$ & $-(100 \%)$ \\
Scola et al. [30]** & 2001 & $166(74.9 \%)$ & $171(59.4 \%)$ \\
\hline
\end{tabular}

* 2-year overall survival; ** supraglottic laryngectomy + supracricoid laryngectomy. $\mathrm{LC}=$ Local control.

Table 4. 5-year local control for supracricoid laryngectomy with cricohyoidopexy

\begin{tabular}{lrrrl}
\hline Authors & Year & n & T stage & 5-year LC, \% \\
\hline Chevalier and Piquet [34] & 1994 & 61 & T1-4 & 79 \\
Naudo et al. [35] & 1997 & 124 & T1-4 & 91 \\
de Vicentiis et al. [36] & 1998 & 149 & T1-4 & 84 \\
Laccourreye et al. [37]* & 1998 & 60 & T3-4 & $91.7(98.3)$ \\
Schwaab et al. [38] & 2001 & 146 & T1-4 & 96 \\
\hline
\end{tabular}

* SCL + neoadjuvant CT. LC = Local control.

the resection of certain supraglottic cancers that would normally be contraindicated for a supraglottic horizontal laryngectomy (usually for glottic extension). Major indications for this procedure include moderately advanced supraglottic tumors with involvement of the infrahyoid epiglottis, anterior commissure, or true vocal cords (with mobile arytenoids). This procedure consists of resection of the entire supraglottis, true vocal cords, thyroid cartilage, and pre-epiglottic and paraglottic spaces. The arytenoids, cricoid, hyoid bone, and recurrent nerves are preserved.

Contraindications for SCL-CHP include: arytenoid fixation, subglottic extension $\geq 10 \mathrm{~mm}$ (anterior) and $\geq 5 \mathrm{~mm}$ (posterior), extensive invasion of pre-epiglottic space, hyoid bone invasion, cricoid CI, and extralaryngeal spread. Local control after SCL-CHP procedures ranges from 79 to $96 \%$ according to the literature (table 4). 
Therapeutic Options for Advanced Glottic and Subglottic Cancer

The treatment options for advanced glottic laryngeal cancer include: radiation therapy, partial laryngectomies, total laryngectomy, and chemoradiation.

Although older series show suboptimal control rates $(20-35 \%)$ and survival rates $(10-50 \%)$ for unselected sets of T3 and T4 tumors treated with radiation alone, it is now recognized that, with proper selection, control rates for T3 lesions treated by RT can approach 80\% [39]. Stage T3 tumors of the glottis may be subdivided into (1) more favorable lesions that may be considered for RT, with surgical salvage for failures, and (2) unfavorable lesions with extensive bilateral involvement, cartilage destruction, or extension to soft tissues of the neck. According to Mendenhall et al. [39], lesions that are generally more suitable for initial management with RT are unilateral, exophytic lesions and do not cause airway obstruction. Comparing the results of primary irradiation versus primary surgery in 108 patients with $\mathrm{T} 3$ glottic tumors treated at the University of Florida, Mendenhall et al. [39] found similar locoregional control rates of $81 \%$ for both therapeutic options. The incidence of severe complications were also comparable (15\%), but the $66 \%$ rate of voice preservation in the RT group was significantly higher than the $2 \%$ associated with the surgical group. Locoregional control rates following definitive RT range from 36 to $71 \%$ in most series, with surgical salvage rates from 30 to $50 \%$ (table 5 ).

Although the indication of performing a salvage total laryngectomy for RT failures is not $100 \%$ shared by the international literature, the dangers of performing a vertical hemilaryngectomy in these circumstances are well known, both from the difficulty in ascertaining that the cord fixation is not associated with thyroid CI and from the known significant increase in complications.

Two different surgical approaches were developed to challenge the gold standard management of advanced laryngeal cancer, represented by total laryngectomy. The less-than-total laryngectomy procedures, despite their published oncological and voice-sparing success, have not become universally accepted, yet.

For glottic tumors, supracricoid partial laryngectomy is associated with cricohyoidoepiglottopexy (CHEP) in order to maintain the airway integrity. Functionally, the base of the tongue and the tip of the epiglottis together with the overhanging arytenoids protect against aspiration, and the moving arytenoids function as a neoglottis producing voice. Indications for SCPL-CHEP include
Table 5. Altered fractionation may improve locoregional control and the probability of voice preservation in $\mathrm{T} 3$ glottic carcinomas

\begin{tabular}{lclc}
\hline \multirow{2}{*}{ Authors } & \multirow{2}{*}{ Patients } & \multicolumn{2}{c}{ Local control, \% } \\
\cline { 3 - 4 } & & initial & ultimate \\
\hline Mendenhall et al. [39] & $15^{*}$ & 53 & 73 \\
& $32^{* *}$ & 71 & 89 \\
Bryant et al. [40] & 55 & 37 & 50 \\
Harwood et al. [41] & 112 & 51 & 77 \\
Wang [42] & 70 & 36 & 57 \\
\hline
\end{tabular}

* Once-a-day treatment; ** twice-a-day treatment.

moderately advanced glottic tumors (T2-3) with extension to the ventricle, false vocal cord, petiole of the epiglottis, anterior aspect of the arytenoid cartilage, and/or impaired vocal cord mobility. T4 glottic tumors with limited thyroid CI are also indications for this procedure. Conversely, contraindications for SCPL-CHEP include arytenoid fixation, subglottic extension beyond that amenable for a vertical hemilaryngectomy $(10 \mathrm{~mm}$ anteriorly and $5 \mathrm{~mm}$ posteriorly, reaching the superior cricoid border), pre-epiglottic space, cricoid CI, invasion of the outer perichondrium of the thyroid cartilage, and extralaryngeal spread. This technique provides a good alternative for moderately advanced glottic cancer removing the paraglottic space, as we can see in the results of the French authors, and the Brazilian National Cancer Institute experience with pT3 and pT4 glottic cancer patients, with higher local control rates in comparison with other conservative options for glottic cancer (table 6). Our previous experience with SCPL-CHEP for laryngeal cancer motivated us to include more advanced glottic cancers in the group of subtotal laryngectomies [43].

Five-year local control rates for advanced glottic cancer treated with SCPL-CHEP ranges from 93.1 to $94.6 \%$ (table 6).

In 1980, Pearson et al. [48] at the Mayo Clinic presented their experience with 'near total' laryngectomy as a surgical alternative to total laryngectomy, as an option for advanced glottic carcinomas. The procedure is clearly more complicated than total laryngectomy, and includes subtotal resection of the larynx preserving one arytenoid and posterior $1 / 3$ of the vocal cord (preserving the ipsilateral recurrent laryngeal nerve) of the uninvolved side of the larynx for voice preservation. Preservation of the lateral segment of the hyoid bone on the uninvolved 
Table 6. Reported local recurrence rate after RT, VPL or SCL-CHEP for glottic carcinoma with impaired motion or fixation of true vocal cord

\begin{tabular}{llllll}
\hline Authors & Year & $\begin{array}{l}\text { Treatment } \\
\text { modality }\end{array}$ & Patients & $\begin{array}{l}\text { Local } \\
\text { failures, \% }\end{array}$ & $\begin{array}{l}\text { Follow-up } \\
\text { years }\end{array}$ \\
\hline Kessler et al. [44] & 1987 & VPL & 27 & 11 & 2 \\
Robson et al. [45] & 1990 & RT & 39 & 33 & 5 \\
Parsons et al. [46] & 1993 & RT & 28 & 33 & 5 \\
Chevalier et al. [47] & 1997 & CHEP & 112 & 5.4 & 5 \\
B.N.C.I. & 2003 & CHEP & 43 & 6.9 & 3 \\
\hline
\end{tabular}

VPL = Vertical partial laryngectomy; SCL-CHEP = supracricoid laryngectomy with cricohyoidoepiglottopexy; $\mathrm{RT}=$ radiotherapy.
Table 7. Disease-free survival rates in 'near total' laryngectomy for advanced laryngeal and hypopharyngeal squamous cell carcinoma patients

\begin{tabular}{lrrll}
\hline Authors & Year & $\begin{array}{c}\text { Pa- } \\
\text { tients }\end{array}$ & $\begin{array}{l}\text { Disease-free } \\
\text { survival, \% }\end{array}$ & $\begin{array}{l}\text { Follow-up } \\
\text { years }\end{array}$ \\
\hline Shenoy et al. [50] & 1997 & 30 & 74 & 5 \\
Pearson et al. [51] & 1998 & 225 & 93 & 5 \\
Pradhan et al. [52] & 2002 & 137 & 70.1 & 3 \\
Bernaldez et al. [53] & 2003 & 87 & 72.4 & 5 \\
B.N.C.I. & 2004 & 53 & 76.8 & 5 \\
\hline
\end{tabular}

hemilarynx maintains the superior laryngeal vessels and nerve, decreasing the risks of aspiration. A shunt is created by using a superiorly based hypopharyngeal flap to fill the resected side of the larynx, thus separating the laryngotracheal remnants from the pharynx. A permanent stoma also results from this procedure. In spite of satisfactory oncological control of disease, only a few institutions were able to achieve satisfactory results. Indications for 'near total' laryngectomy include: T3 or early T4 glottic carcinomas that did not involve the interarytenoid space or vocal process of the opposite arytenoid; T3 supraglottic carcinoma with a fixed vocal cord in which a supraglottic laryngectomy could not be performed; T2-3 pyriform sinus carcinomas; salvage after RT for early glottic lesions in which a hemilaryngectomy could not be performed; and in large hypopharyngeal lesions in which the larynx would be sacrificed to prevent aspiration. Complications associated with this procedure include aspiration, dilated shunt appendix, and inadequate tracheopharyngeal shunt function [49].

Five-year locoregional control rates for 'near total' laryngectomy patients ranges from 70.1 to $93 \%$ accord- ing to the international literature (table 7). These results could be explained by the inclusion or hypopharyngeal cancer patients in all series. Lung-powered 'shunt' voice is acquired in most patients from the international series ranging from 76 to $93 \%$, in periods ranging from 7 to 28 days [50-55]. Larynx cancer patients seem to have a better oncological/functional outcome in comparison with hypopharyngeal cancer patients $[50-53,55]$.

\section{Radical Surgery for Advanced Laryngeal Cancer}

Total laryngectomy still remains as a gold standard for the treatment of advanced laryngeal cancer in many centers around the world. More advanced or the so-called 'unfavorable' laryngeal cancers often require total laryngectomy and bilateral neck dissection alone or combined with adjuvant RT. Advanced tumors involving the arytenoids or the interarytenoid space, tumors grossly involving the subglottic compartment (particularly in its posterolateral aspect), compromising the postcricoid area and/or lateral aspect of the hypopharynx are not amenable for partial/subtotal laryngectomies. Extralaryngeal spread (ELS) is a common finding as well as lymph node metastases. Gross subglottic extension and involvement of the paratracheal lymph nodes are considered important risk factors for tracheal stomal recurrence. Yuen et al. [56], in 1984, published a series of 185 patients with $\mathrm{T} 3$ glottic cancer treated with surgery alone (155 patients) or combined with adjuvant RT (30 patients). All patients had total laryngectomy. They found a 17\% locoregional failure rate. DeSanto [57], in 1984, found an overall local and regional failure rate of 6 and $15 \%$, respectively, in $104 \mathrm{~T} 3$ glottic cancer patients treat- 
Table 8. Locoregional control in advanced laryngeal cancer patients treated with total laryngectomy

\begin{tabular}{llllll}
\hline Authors & Year & $\begin{array}{l}\text { Type of } \\
\text { treatment }\end{array}$ & Patients & \multicolumn{2}{l}{ Locoregional } \\
\cline { 5 - 6 } & & & control, \% & stage \\
\hline Yuen et al. [56] & 1984 & TL/TL + ND & 185 & 83 & III/IV* \\
DeSanto [57] & 1984 & TL & 106 & 79 & III/IV* \\
Razack et al. [58] & 1989 & TL/TL + ND & 128 & 53 & III/IV* \\
Mendenhall et al. [39] & 1992 & TL/RT & 52 & 75 & III/IV* \\
B.N.C.I. [59] & 2000 & TL + ND + RT & 102 & 67.6 & III/IV \\
\hline
\end{tabular}

$\mathrm{TL}=$ Total laryngectomy $; \mathrm{ND}=$ neck dissection; $\mathrm{RT}=$ radiotherapy.

* Mostly T3 carcinomas. ed with radical surgery. Razack et al. [58], in 1989, on a retrospective series of 128 T3-4 glottic carcinoma patients treated by total laryngectomy alone $(46 \%)$, or total laryngectomy plus neck dissection (54\%) found a 53\% 5year disease-free survival rate. Mendenhall et al. [39], in 1992, comparing the results of surgery versus RT for advanced laryngeal cancer found a $75 \%$ locoregional control rate for patients who underwent total laryngectomy plus adjuvant RT.

In 2000 we presented our experience with 102 patients with stage III and IV laryngeal cancer who underwent a 'wide field' total laryngectomy with postoperative RT at the Brazilian National Cancer Institute. [59]. With the purpose of identifying possible factors of prognostic impact, patients were classified in: T3N0M0 (21/20.6\%), T4N0M0 with CI (29/28.4\%), T4N0M0 with ELS $(25 / 24.5 \%)$, and T3-4N2M0 (27/26.5\%). The incidence of patients in each group was similar in this cohort. Most of the patients $(81.3 \%)$ had supraglottic or transglottic carcinomas. Comparison between the groups according to their 3-year disease-free survival revealed a statistically significant difference between the T3 and T4 (CI) groups in comparison with the T4 (ELS) and the N+ group. These findings confirm the adverse prognostic impact of regional metastases and, at the same time, question the importance of $\mathrm{CI}$ as a negative factor in surgically treated laryngeal cancer. The $80 \%$ disease-free survival rate achieved in Stage III and Stage IV (CI group) laryngeal carcinoma patients was significantly better in comparison with the $67 \%$ rate achieved in Stage IV (ELS and $N+$ groups) patients $(p=0.02)$. Five-year local control rates for advanced laryngeal cancer treated with total laryngectomy ranges from 53 to $83 \%$ (table 8 ).

\section{Chemotherapy and Radiation Therapy for Advanced Laryngeal Cancer}

Hong et al. [60] performed the first study on primary chemotherapy (CT) and organ preservation specifically with regard to laryngeal cancer. They found that CT response predicted RT response and, in addition to that, they observed that complete or partial response was a statistically important factor regarding local control rates. Their observations led to the design of the Veterans Affairs trial focusing on patients with resectable stage III and IV laryngeal cancer, usually treated with total laryngectomy. The estimated 3-year survival rates were 56\% for the surgery-RT arm and 53\% for the CT-RT arm group. There were no significant differences in survival based on larynx subsite or stage, but $62 \%$ of patients in the CT-RT arm were able to preserve their larynges. Predictive factors of higher control rates with CT plus RT includes moderately advanced stages, clinically negative neck, and effective response to CT. In 1991 Pfister et al. [61] and Wolf et al. [62] published their results with neoadjuvant CT (cisplatin-based) and RT. The first did a nonrandomized study of CT plus RT for laryngeal and pharyngeal carcinomas, while Wolf did a larger randomized study (VA laryngeal cancer study group). Both reached similar results in organ preservation (2-years w/ larynx of 59 and 68\%) and overall survival rates (2-years overall survival of 79 and 68\%) showing no benefit in survival in comparison with the results of surgery plus RT. Many of the questions regarding the role of CT in the treatment of advanced laryngeal cancer are still unanswered, mainly because the heterogeneity of the series published in the literature, although most of the trials focused on survival with preservation of laryngeal function as the primary endpoint. Numerous randomized trials have compared RT with combinations of CT plus RT. 
Most of these trials are platinum-based regimens, often in association with 5-FU and radical RT. Most of the trials demonstrated a significant benefit for CT plus RT both in survival rates as well as in locoregional control rates. Analysis, reported by El-Sayed and Nelson [63] in 1996 included 25 studies in which 4,075 patients with head and neck squamous cell carcinomas were randomized to receive local definitive therapy versus the same treatment with the addition of CT. Nine of the studies involved neoadjuvant $\mathrm{CT}, 5$ involved neoadjuvant $\mathrm{CT}$ plus maintenance treatment, and 11 involved concurrent $\mathrm{CT}$ plus $\mathrm{RT}$. The addition of CT reduced the mortality rate by $11 \%$ in the total group. Concurrent treatment reduced mortality by $22 \%$. In the second meta-analysis known as MACH-NC (1998) [64], in France, the authors utilized updated data from 63 randomized trials including a total of 10,850 patients. Eight trials involved adjuvant CT, 31 involved neoadjuvant treatment, and 26 involved concurrent CT. Median follow-up was 6 years and CT rendered an absolute survival benefit of $4 \%$ (from 32 to $36 \%$ ) at 5 -year follow-up. Virtually all of that benefit had been derived from the concurrent trials in which there was absolute survival benefit of $8 \%$ at 5 years. A recently published phase III trial to preserve the larynx (The Intergroup Trial RTOG91-11) [65], compared induction CT and RT versus concomitant chemoradiation versus RT alone in 547 patients with stage III and IV potentially operable cancer of the larynx. Of note, initial laryngeal preservation was provided to the patients in all three groups but, differently from other similar studies, patients with large T4 tumors were excluded. The 2- and 5 -year survival rates were similar among the three groups; however, patients treated with concurrent CT plus RT had higher rates of survival with a functioning larynx as well as higher rates of laryngeal preservation and local control in comparison with the other two groups. Although these data confirm that initial treatment aimed at laryngeal preservation is a realistic and feasible option for most patients with advanced/moderately advanced laryngeal cancer, there is a large group of patients with advanced laryngeal cancer who are candidates for organpreserving surgical techniques, such as endoscopic transoral resection, and open partial or less-than-total laryngectomies avoiding total laryngectomy. It is important to mention that, by not including options involving lessthan-total laryngectomy, authors may leave readers with the impression that total laryngectomy is the only surgical option for laryngeal cancer. It is the standard of care to discuss the surgical and nonsurgical organ-preserving options with every larynx cancer patient candidate for surgical approaches that preserve the larynx and thus allowing these patients to participate in the choice of appropriate treatment [66].

\section{References}

1 Kirchner JA: Growth and spread of laryngeal cancer as related to partial laryngectomy. Laryngoscope $1975 ; 85: 1516-1521$.

$\checkmark 2$ Kirchner JA: Glottic-supraglottic barrier: Fact or fantasy? Ann Otol Rhinol Laryngol 1997; 106:700-704.

-3 Myers EN, Alvi A: Management of carcinoma of the supraglottic larynx: Evolution, current concepts, and future trends. Laryngoscope 1996;106:559-567.

4 Tucker GF, Smith HR: A histological demonstration of the development of laryngeal connective tissue compartments. Trans Am Acad Ophthalmol Otolaryngol 1982;66:308-318.

5 Coutard H, Valat A: Considerations sur le cancer de la bande et la cavite ventriculaire du larynx. Ann d mal de l'oreille de larynx 1927; 2:469-512.

6 Bocca E, Pignataro O, Mosciaro O: Supraglottic surgery of the larynx. Ann Otol Rhinol Laryngol 1968;77:1005-1026.

7 Mendenhall WM, Parsons JT, Stringer SP, Cassisi NJ: Radiotherapy for carcinoma of the supraglottis. Otolaryngol Clin North Am 1997; 30:145-161.
-8 Harwood AR, Hill RP: Supraglottic laryngeal carcinoma. Int J Radiat Oncol Biol Phys 1983; 9:1759-1760.

$\checkmark 9$ Mendenhall WM, Parsons JT, Mancuso AA, et al: Radiation therapy for squamous cell carcinoma of the supraglottic larynx: An alternative to surgery. Head Neck 1996;18:24-35.

10 Daugaard BJ, Sand HH: Primary radiotherapy of carcinoma of the supraglottic larynx - A multivariate analysis of prognostic factors. Int J Radiat Oncol Biol Phys 1998;41:355-360.

$\checkmark 11$ Santos CR, Kowalski LP, Magrin J, et al: Prognostic factors in supraglottic carcinoma patients treated by surgery or radiotherapy. Ann Otol Rhinol Laryngol 1998;107:697-702.

12 Sykes AJ, Slevin NJ, Gupta NK, Brewster AE: 331 cases of clinically node-negative supraglottic carcinoma of the larynx: A study of a modest size fixed radiotherapy approach. Int J Radiat Oncol Biol Phys 2000;46:1109-1115.

13 Hinerman RW, Mendenhall WM, Amdur RJ, et al: Carcinoma of the supraglottic larynx: Treatment results with radiotherapy alone or with planned neck dissection. Head Neck 2002;24:456-467.
14 Strong MS, Jako GJ: Laser surgery in the larynx. Early clinical experience with continuous CO2 laser. Ann Otol Rhinol Laryngol 1972;81: 791-798.

15 Davis RK, Shapshay SM, Strong MS, Hyams VJ: Transoral partial supraglottic resection using the $\mathrm{CO}_{2}$ laser. Laryngoscope 1983;93:429_ 432.

16 Steiner W: Experience in endoscopic laser surgery of malignant tumours of the upper aerodigestive tract. Adv Otorhinolaryngol 1988;39: 135-144.

17 Zeitels SM, Koufman JA, Davis RK, Vaughan CW: Endoscopic treatment of supraglottic and hypopharynx cancer. Laryngoscope 1994;104: 71-78.

18 Davis RK, Kelly SM, Hayes J: Endoscopic $\mathrm{CO}_{2}$ laser excisional biopsy of early supraglottic cancer. Laryngoscope 1991:101:680-683.

19 Steiner W: Results of curative laser microsurgery of laryngeal carcinomas. Am J Otolaryngol 1993;14:116-121. 
20 Rudert HH, Werner JA, Hoft S: Transoral carbon dioxide laser resection of supraglottic carcinoma. Ann Otol Rhinol Laryngol 1999;108: 819-827.

21 Alonso JM: Conservative surgery of cancer of the larynx. Trans Am Acad Ophthalmol Otolaryngol 1947;51:633-642.

22 Ogura JH, Sessions DG, Spector GJ: Conservation surgery for epidermoid carcinoma of the supraglottic larynx. Laryngoscope 1975;85: 1808-1815.

23 Som ML: Conservation surgery for carcinoma of the supraglottis. J Laryngol Otol 1970;84: 655-678.

24 Ogura JH, Marks JE, Freeman RB: Results of conservation surgery for cancers of supraglottis and pyriform sinus. Laryngoscope 1980;90: 591-600.

-25 Ogura JH, Dedo HH: Glottic reconstruction following subtotal glottic-supraglottic laryngectomy. Laryngoscope 1965;75:865-876.

-26 Bocca E, Pignataro O, Oldini C: Supraglottic laryngectomy: 30 years of experience. Ann Otol Rhinol Laryngol 1983;92:14-18.

$\checkmark 27$ Burstein FD, Calcaterra TC: Supraglottic laryngectomy: Series report and analysis of results. Laryngoscope 1985;95:833-836.

28 Lee NK, Goepfert H, Wendt CD: Supraglottic laryngectomy for intermediate-stage cancer: U.T. M.D. Anderson Cancer Center experience with combined therapy. Laryngoscope 1990;100:831-836.

-29 Isaacs JH, Slattery WH, Mendenhall WM, Cassisi NJ: Supraglottic laryngectomy. Am J Otolaryngol 1998;19:118-123.

- 30 Scola B, Fernandez-Vega M, Martinez T, et al: Management of cancer of the supraglottis. Otolaryngol Head Neck Surg 2001;124:195198

-31 Majer H, Rieder A: Technique de la laryngectomie permetant de conserver la perméabilité respiratoire: La cricohyoidopexie. Ann Otolaryngol Chir Cervicofac 1959;76:677-683.

- 32 Piquet JJ, Desaulty A, Decroix G: La Cricohyoido-epiglotto-pexie. Technique opératoire et résultats fonctionnels. Ann Otolaryngol Chir Cervicofac 1974;91:681-690.

- 33 Laccourreye H, Laccourreye O, Weinstein G, Menard M, Brasnu D: Supracricoid laryngectomy with cricohyoidopexy: A partial laryngeal procedure for selected supraglottic and transglottic carcinomas. Laryngoscope 1990; 100:735-741.

-34 Chevalier D, Piquet JJ: Subtotal laryngectomy with cricohyoidopexy for supraglottic carcinoma: Review of 61 cases. Am J Surg 1994;168: 472-473.

- 35 Naudo P, Laccourreye O, Weinstein G, et al: Functional outcome and prognostic factors after supracricoid partial laryngectomy with cricohyoidopexy. Ann Otol Rhinol Laryngol 1997;106:291-296.

-36 de Vicentiis M, Minni A, Gallo A, Di Nardo A: Supracricoid partial laryngectomies: Oncologic and functional results. Head Neck 1998; 20:504-509.
37 Laccourreye O, Brasnu D, Biacabe B, et al: Neo-adjuvant chemotherapy and supracricoid partial laryngectomy with cricohyoidopexy for advanced endolaryngeal carcinoma classified as T3-T4: 5-year oncologic results. Head Neck 1998;20:595-599.

- 38 Schwaab G, Kolb F, Julieron M, et al: Subtotal laryngectomy with cricohyoidopexy as first treatment procedure for supraglottic carcinoma: Institut Goustave-Roussy experience (146 cases, 1974-1997). Eur Arch Otorinolaryngol 2001;258:246-249.

39 Mendenhall WM, Parsons JT, Stringer SP, et al: Stage T3 squamous cell carcinoma of the glottic larynx: A comparison of laryngectomy and irradiation. Int J Radiat Oncol Biol Phys 1992;23:725-732.

40 Bryant GP, Poulsen MG, Tripcony L, et al: Treatment decisions in T3N0M0 glottic carcinoma. Int J Radiat Oncol Biol Phys 1995;31: 285-293.

41 Harwood AR, Hawkins NV, Beale FA, et al: Management of advanced glottic cancer: A 10year review of the Toronto experience. Int $\mathrm{J}$ Radiat Oncol Biol Phys 1979;5:899-904.

42 Wang CC: Radiation therapy of laryngeal tumors; in Thawley SE, Panje WR (eds): Comprehensive Management of Head and Neck Tumors. Philadelphia, WB Saunders, 1987.

43 Lima RA, Freitas EQ, Kligerman J, et al: Laringectomia Supracricóide (CHEP) para Câncer Glótico. Rev Col Bras Cir 2001;28:254258.

44 Kessler DJ, Trapp TK, Calcaterra TC: The treatment of T3 glottic carcinoma with vertical partial laryngectomy. Arch Otolaryngol Head Neck Surg 1987;113:1196-1199.

45 Robson NL, Oswal VH, Flood LM: Radiation therapy of laryngeal cancer: A twenty year experience. J Laryngol Otol 1990;104:699-703.

46 Parsons JT, Mendenhall WM, Stringer SP, Cassisi NJ, Million RR: Twice-a-day radiotherapy for squamous cell carcinoma of the head and neck: The University of Florida experience. Head Neck 1993;15:87-96.

47 Chevalier D, Laccourreye O, Brasnu D, Laccourreye H, Piquet JJ: Cricohyoidoepiglottopexy for glottic carcinoma with fixation or impaired motion of the true vocal cord: 5-year oncologic results with 112 patients. Ann Otol Rhinol Laryngol 1997;106:364-369.

48 Pearson BW, Woods RD, Hartman DE: Extended hemilaryngectomy for T3 glottic carcinoma with preservation of speech and swallowing. Laryngoscope 1980;90:1950-1954.

49 Levine PA, Debo RF, Reibel JF: Pearson neartotal laryngectomy: A reproducible speaking shunt. Head Neck 1994;16:323-325.

50 Shenoy AM, Plinkert PK, Nanjundappa N, et al: Functional utility and oncologic safety of near-total laryngectomy with tracheopharyngeal speech shunt in a third world oncologic center. Eur Arch Otorhinolaryngol 1997;254: 128-132.

-51 Pearson BW, DeSanto LW, Olsen KD, Salassa JR: Results in near-total laryngectomy. Ann Otol Rhinol Laryngol 1998;107:820-825.
52 Pradhan SA, D’Cruz AK, Pai PS, Mohiyuddin A: Near-total laryngectomy in advanced laryngeal and pyriform cancers. Laryngoscope 2002; 112:375-380

-53 Bernaldez R, Garcia-Pallares M, Morera E, et al: Oncologic and functional results of near-total laryngectomy. Otolaryngol Head Neck Surg 2003; 128:700-705.

54 Robbins KT, Michaels L: Feasibility of subtotal laryngectomy based on whole-organ examination. Arch Otolaryngol 1985;111:356-360.

55 Lima RA, Freitas EQ, Kligerman J, et al: Neartotal laryngectomy for treatment of advanced laryngeal cancer. Am J Surg 1997;174:490491.

-56 Yuen A, Medina JE, Goepfert H, Fletcher GH: Management of stage T3 and T4 glottic carcinomas. Am J Surg 1984;148:467-472.

57 DeSanto LW: T3 glottic cancer: Options and consequences of the options. Laryngoscope 1984;94:1311-1315.

58 Razack MS, Maipang T, Sako K, et al: Management of advanced glottic carcinomas. Am J Surg 1989;158:318-320.

59 Dias FL, Kligerman J, Lima RA, et al: Prognostic significance of cartilage invasion in surgically treated advanced laryngeal cancer (abstract). Final Program and Abstract Book - 5th International Conference on Head and Neck Cancer 1, 2000.

60 Hong WK, O’Donoghue GM, Sheetz S, et al: Sequential response patterns to chemotherapy and radiotherapy in head and neck cancer: Potential impact of treatment in advanced laryngeal cancer. Prog Clin Biol Res 1985;201:191197.

-61 Pfister DG, Strong E, Harrison L, et al: Larynx preservation with combined chemotherapy and radiation therapy in advanced but resectable head and neck cancer. J Clin Oncol 1991; 9:850-859.

62 Wolf GT, Hong WK, Fisher SG, et al: Induction chemotherapy plus radiation compared with surgery plus radiation in patients with advanced laryngeal cancer. N Engl J Med 1991; 324:1685-1690.

63 El Sayed S, Nelson N: Adjuvant and adjunctive chemotherapy in the management of squamous cell carcinoma of the head and neck region. A meta-analysis of prospective and randomized trials. J Clin Oncol 1996;14:838847.

64 Lefebvre JL, Wolf G, Luboinski B: Meta-analysis of chemotherapy in head and neck cancer (MACH-NC): (2) larynx preservation using neoadjuvant chemotherapy (CT) in laryngeal and hypopharyngeal carcinoma. Proc ASCO 1473, 1998.

65 Forastiere AA, Goepfert H, Maor M, et al: Concurrent chemotherapy and radiotherapy for organ preservation in advanced laryngeal cancer. N Engl J Med 2003;349:2091-2098.

66 Weinstein GS, Myers EN, Shapshay SM: Nonsurgical treatment of laryngeal cancer. $\mathrm{N}$ Engl J Med 2004;350:1049-1053. 